Contract No. and Disclaimer:

This manuscript has been authored by Savannah River Nuclear Solutions, LLC under Contract No. DE-AC09-08SR22470 with the U.S. Department of Energy. The United States Government retains and the publisher, by accepting this article for publication, acknowledges that the United States Government retains a non-exclusive, paid-up, irrevocable, worldwide license to publish or reproduce the published form of this work, or allow others to do so, for United States Government purposes. 
Proceedings of the ASME 2011 Pressure Vessels and Piping Division Conference PVP 2011

July 17-21, 2011, Baltimore, Maryland USA

PVP2011-57006

\section{HYDROGEN CONCENTRATIONS DURING STORAGE OF 3013 OXIDE SAMPLES}

\author{
N. M. Askew \\ Savannah River National Laboratory \\ Savannah River Site \\ Aiken, SC 29808 \\ (803) 725-8053 \\ neal.askew@srnl.doe.gov
}

\author{
J. E. Laurinat \\ Savannah River National Laboratory \\ Savannah River Site \\ Aiken, SC 29808 \\ (803) 725-8052 \\ james.laurinat@srnl.doe.gov
}

\author{
S. J. Hensel \\ Savannah River National Laboratory \\ Savannah River Site \\ Aiken, SC 29808 \\ (803) 725-8440 \\ steve.hensel@srnl.doe.gov
}

\begin{abstract}
As part of a surveillance program intended to ensure the safe storage of plutonium bearing nuclear materials in the Savannah River Site (SRS) K-Area Materials Storage (KAMS), samples of these materials are shipped to Savannah River National Laboratory (SRNL) for analysis. These samples are in the form of solids or powders which will have absorbed moisture. Potentially flammable hydrogen gas is generated due to radiolysis of the moisture. The samples are shipped for processing after chemical analysis. To preclude the possibility of a hydrogen deflagration or detonation inside the shipping containers, the shipping times are limited to ensure that hydrogen concentration in the vapor space of every layer of confinement is below the lower flammability limit of 4 volume percent (vol\%) [1]. This study presents an analysis of the rate of hydrogen accumulation due to radiolysis and calculation of allowable shipping times for typical KAMS materials.
\end{abstract}

Keywords: Hydrogen Generation, Plutonium Oxide Storage

\section{INTRODUCTION}

For shipment, the KAMS samples are placed in an inner slip-lid can, bagged out in two layers of plastic bags, and placed into an outer slip-lid can. The packaged materials are shipped in Croft Safdrums. A Croft Safdrum consists of an outer drum containing an energy absorbing material and a steel containment vessel. The shipping time is limited to ensure that hydrogen concentration of the vapor space of every layer of confinement remains below the lower flammability limit of 4 volume percent (vol\%) [1]. The distance from the K-Area Materials Storage to the SRNL is less than 20 miles as both are within the SRS. Actual transport times are relatively short, however, shipping times begin when samples are loaded into the drum and end upon removal of the samples from the drum.
The nominal void volume inside the Croft Safdrum containment vessel is $7.5 \mathrm{gal}$ or 28.4 liters. There may be some packing material placed around the outer slip-lid can after it is placed in the Croft Safdrum. It is conservatively assumed that the two slip-lid cans, the two plastic bags, and any packing material do not displace more than 13.4 liters. Therefore, the void volume inside the Croft Safdrum is assumed to be 15 liters.

The inner can is inserted into a bag-out bag and the end of the bag-out bag is taped closed. This taped closure is formed by twisting the bag and spiraling several layers of tape over the twisted portion. The first bag may have a taped closure at both ends. A bag with two taped closures would allow for hydrogen to escape more readily than a bag with a single closure. This study conservatively assumes a single closure. The first bag is then placed into a second bag which also is taped closed. Alternatively, filtered bags may be used. The double bagged item then is placed in the outer slip-lid can. The interior volumes of the inner slip-lid can, the outer slip-lid can, and both bag enclosures are assumed to be 0.3 liters.

\section{NOMENCLATURE}

$\begin{array}{ll}\mathrm{R} & \text { gas constant } \\ \mathrm{T} & \begin{array}{l}\text { absolute temperature } \\ \text { volume } \\ \mathrm{V}\end{array} \\ \mathrm{r} & \begin{array}{l}\text { resistance to hydrogen diffusion } \\ \text { (moles/day/mole fraction) }\end{array} \\ \mathrm{T} & \text { time } \\ \overline{\mathrm{p}}_{\mathrm{H}} & \text { partial pressure of hydrogen }\end{array}$

Subscripts 1 - 5 refer to regions described in text.

\section{MODELING APPROACH AND SOLUTION METHOD}

The analysis of the rate of radiolytic hydrogen generation

The United States Government retains, and by accepting the article for publication, the publisher acknowledges that the United States Government retains, a non-exclusive, paid-up, irrevocable worldwide licence to publish or reproduce the published form of this work, or allow others to do so, for United States Government purposes. 
is based on maximum bounding measured rates for typical plutonium bearing oxide materials. These rates depend on the $G$ value for the plutonium oxide bearing materials, the amount of energy released by the radioactive materials (i.e. heat generation rate), and the amount of adsorbed moisture. The number of molecules of hydrogen formed for a given amount of energy is referred to as the $\mathrm{G}$ value. The units for the g-value are the number of molecules formed per $100 \mathrm{eV}$ of energy deposited into a material by ionizing radiation. G values have been calculated from experimentally-determined hydrogen generation rates for plutonium bearing materials in the Materials Identification and Surveillance Program (MIS). At $0.5 \%$ weight percent $(\mathrm{wt} \%)$ moisture, and allowing for the recommended uncertainty, the $G$ values for hydrogen generation in MIS materials vary from $6.61 \times 10^{-6}$ to $1.31 \times 10^{-2}$ molecules of hydrogen per $100 \mathrm{eV}$. These $\mathrm{G}$ values are calculated on the basis of total alpha energy generated by the materials. G values can also be calculated on the basis of the estimated alpha energy deposited into the adsorbed water. As a first approximation, the $G$ values determined for the three surrogate MIS materials scale roughly linearly with the moisture content $[2,3]$. Scaled linearly to $3 \%$ moisture, the highest g-value for any of the MIS materials considered is 7.86 x $10^{-2}$ molecules of hydrogen per $100 \mathrm{eV}$.

The g-value for radiolysis of water adsorbed onto plutonium dioxide appears to increase rapidly with increasing moisture. The highest g-value for radiolysis of moisture on plutonium dioxide reported in the literature is 8.6 molecules per $100 \mathrm{eV}$ absorbed by the water, as shown by Figure $1[2,3,4]$. The relative gas generation rates reported in Reference 4 are significantly higher than those for similar experiments conducted at SRNL. In order to bound the potential hydrogen generation rate, the g-value from Reference 4 will be used. The g-value from Reference 4 for oxide with 3\% moisture, expressed in terms of molecules of hydrogen generated per 100 $\mathrm{eV}$ of total energy, is 0.33 . This value is higher than the gvalue of $7.86 \times 10^{-2}$ derived from linear extrapolation of the highest g-value found for MIS materials. The higher g-value (0.33) is expected to be conservative for the worst case (highest) effective g-value for the materials of interest with 3\% moisture content.

Based on operating controls established in KAMS, the maximum moisture content of samples shipped to SRNL is expected to be no more than $3 \mathrm{wt} \%$. The $3 \%$ moisture is due primarily to moisture associated with chloride compounds. The materials returned for processing will be conservatively assumed to be bounded by $3 \%$ moisture.

The energy generated by plutonium bearing oxides depends on the plutonium isotopics and the presence of other radioactive materials such as americium. Uranium-235 and uranium-238 have much lower specific activities than plutonium, so the hydrogen generation due to these common uranium isotopes is negligible. The plutonium bearing materials in the MIS database have a wide range of specific powers. Of the approximately 120 packaged items that are scheduled for destructive evaluation as part of the $3013 \mathrm{DE}$ program, all but five have specific powers less than 0.0025 watts per gram. The highest specific power of the packaged items scheduled for destructive evaluation is 0.00846 watts per gram. These specific powers are based upon the total grams of material, not just the grams of fissile material. Weapons grade plutonium has a specific power of 0.00281 watts per gram of plutonium [6].

For example, of the 3013 cans scheduled for sampling in FY 2008, the highest specific energy was 0.01 watts per gram of plutonium (due to high americium content). In order to bound the specific powers for the materials that may be stored, this specific power of 0.01 watts per gram of plutonium was used in this calculation. The specific power of the MIS materials could change with time due to the in-growth of isotopes such as americium-241.

In order to calculate the hydrogen concentration in the Croft Safdrum, it is assumed the Croft Safdrum is sealed at a temperature no higher than $30^{\circ} \mathrm{C}\left(86^{\circ} \mathrm{F}\right)$. The actual temperature will probably be lower, as the Croft Safdrum will be sealed indoors in a heated and air-conditioned environment.

The rate of hydrogen formation depends upon the rate of energy deposition and the type of material. The energy deposition depends on the quantity and specific energy of the material being shipped. The energy deposition can be calculated using the equation:

$$
\begin{aligned}
& \text { energy per day }=\text { watts per gram * mass of } \\
& \text { material (in grams) } / 1.602 \times 10^{-13} \mathrm{~W} \mathrm{~s} / \mathrm{MeV} * \\
& 86400 \mathrm{~s} / \text { day }
\end{aligned}
$$

The hydrogen generation rate is

molecules $\mathrm{H}_{2}$ per day $=$ g-value $($ molecules $/ 100 \mathrm{eV}) *$ energy deposited $(\mathrm{MeV} /$ day $) * 10000$

or

moles $\mathrm{H}_{2}$ per day $=$ molecules per day /

$6.022 \times 10^{23} \mathrm{molecules} / \mathrm{mole}$

The hydrogen escapes the packaging by diffusion. It must pass through the air gap between the can and its slip lid and the plastic bags. Diffusion through an air gap is much faster than through a polymer. The tape that fastens the lids to the inner can does not form an airtight seal, thus the taped lids will not provide significant resistance to the diffusion of hydrogen. However, a slip-lid can that has its lid carefully taped so there is no air gap can provide a significant resistance to diffusion. The Rocky Flats Plant has measured the diffusion rate through taped slip-lid cans. The diffusion rate for a slip lid can taped 
with vinyl tape was measured to be $1.2 \times 10^{-7} \mathrm{~mole} / \mathrm{sec} / \mathrm{mole}$ fraction for the release rate of hydrogen through the taped closures [7]. The same can had a diffusion rate of $1.03 \times 10^{-5}$ mole $/ \mathrm{sec} / \mathrm{mole}$ fraction when untaped, an increase of two orders of magnitude. These measurements were performed at atmospheric pressure. All diffusion calculations for this study are performed under the assumption that the resistances remain constant at their atmospheric pressure values.

The hydrogen will diffuse through the two plastic bags, or through the air space in the taped closures. The diffusion rate of hydrogen through a polymer is very low compared to that of the diffusion through air. The taped closures provide a path for hydrogen to escape the plastic bags by diffusion through air. In order to calculate the hydrogen diffusion through a taped closure, a value for the cross-sectional area of the diffusion path would be required. This difficulty is avoided if the hydrogen diffusion rate is experimentally determined. Such experiments were conducted as part of the effort to qualify the TRUPACT-II Shipping Container [8]. In these experiments, the hydrogen diffusion rate was measured for PVC and polyethylene bags. These bags were taped closed forming horsetails using the SRS standard practice. The TRUPACT-II analysis used 5.58 $10^{-7}$ mole/sec/mole fraction for the release rate of hydrogen through the taped closures. This was the lowest of the experimentally determined values, and neglected diffusion through the plastic bags.

In order to reduce the resistance to hydrogen diffusion for this application, filtered bags may be used. The filtered bags use a NucFil ${ }^{\circledR}-036$ DA filter. According to the manufacturer's specifications, this filter allows hydrogen to diffuse at no less than $9.0 \times 10^{-5} \mathrm{~mole} / \mathrm{sec} / \mathrm{mole}$ fraction.

The two cans and two plastic bags divide the shipping container into five regions. The first is the volume inside the inner can, the second is the volume between the inner can and the inner bag, the third is the volume between the two bags, the fourth is the volume between the outer bag and the outer can, and the fifth is the volume outside the outer can. The changes in the partial pressure of hydrogen with time in each of these regions are described by the following five equations:

$$
\begin{aligned}
& \frac{\mathrm{d} \overline{\mathrm{p}}_{\mathrm{H}_{1}}}{\mathrm{dt}}=\frac{\mathrm{RT}}{\mathrm{V}_{1}}\left(-\mathrm{r}_{1-2}\left(\overline{\mathrm{p}}_{\mathrm{H}_{1}}-\overline{\mathrm{p}}_{\mathrm{H}_{2}}\right)+\mathrm{G}\right) \\
& \frac{\mathrm{d} \overline{\mathrm{p}}_{\mathrm{H}_{2}}}{\mathrm{dt}}=\frac{\mathrm{RT}}{\mathrm{V}_{2}}\left(\mathrm{r}_{1-2}\left(\overline{\mathrm{p}}_{\mathrm{H}_{1}}-\overline{\mathrm{p}}_{\mathrm{H}_{2}}\right)-\mathrm{r}_{2-3}\left(\overline{\mathrm{p}}_{\mathrm{H}_{2}}-\overline{\mathrm{p}}_{\mathrm{H}_{3}}\right)\right)
\end{aligned}
$$

\footnotetext{
${ }^{\circledR}$ NucFil is a registered trademark of Nuclear Filter Technology of Golden, Colorado.
}

$$
\begin{aligned}
& \frac{\mathrm{d} \overline{\mathrm{p}}_{\mathrm{H}_{3}}}{\mathrm{dt}}=\frac{\mathrm{RT}}{\mathrm{V}_{3}}\left(\mathrm{r}_{2-3}\left(\overline{\mathrm{p}}_{\mathrm{H}_{2}}-\overline{\mathrm{p}}_{\mathrm{H}_{3}}\right)-\mathrm{r}_{3-4}\left(\overline{\mathrm{p}}_{\mathrm{H}_{3}}-\overline{\mathrm{p}}_{\mathrm{H}_{4}}\right)\right) \\
& \frac{\mathrm{d} \overline{\mathrm{p}}_{\mathrm{H}_{4}}}{\mathrm{dt}}=\frac{\mathrm{RT}}{\mathrm{V}_{4}}\left(\mathrm{r}_{3-4}\left(\overline{\mathrm{p}}_{\mathrm{H}_{3}}-\overline{\mathrm{p}}_{\mathrm{H}_{4}}\right)-\mathrm{r}_{4-5}\left(\overline{\mathrm{p}}_{\mathrm{H}_{4}}-\overline{\mathrm{p}}_{\mathrm{H}_{5}}\right)\right) \\
& \frac{\mathrm{d} \overline{\mathrm{p}}_{\mathrm{H}_{5}}}{\mathrm{dt}}=\frac{\mathrm{RT}}{\mathrm{V}_{5}}\left(\mathrm{r}_{4-5}\left(\overline{\mathrm{p}}_{\mathrm{H}_{4}}-\overline{\mathrm{p}}_{\mathrm{H}_{5}}\right)\right)
\end{aligned}
$$

It is assumed that the outer slip-lid can is packaged a sufficient length of time prior to loading into the Croft Safdrum to allow the hydrogen concentrations inside the can to reach equilibrium. Thus the initial conditions for the solution of equations 4 through 8 are calculated by setting the time derivatives and the hydrogen concentration inside the Croft Safdrum to zero.

\section{RESULTS AND DISCUSSIONS}

Allowable shipping times can be limited to prevent the accumulation of flammable concentrations of radiolytically generated hydrogen inside shipping packages. In order to provide a reasonable shipping time, it may be necessary to limit the amount of material shipped, control the amount of moisture, or to provide a package configuration that is less restrictive to hydrogen diffusion. For samples with moisture contents no higher than $3 \mathrm{wt} \%$, with a specific power of 0.01 watts/gram and a conservative $\mathrm{G}$ value of 0.33 , the hydrogen generation rate is $7.39 \times 10^{-4}$ moles per day for 25 grams of fissile material. For the more restrictive case considered here, with two taped, twist-sealed bags, this hydrogen generation rate leads to a steady-state hydrogen concentration inside the innermost layer of confinement of $3.2 \%$ before the material is placed in the Croft Safdrum. This high initial concentration limits the allowable shipping time for the Croft Safdrum to 8 days before the innermost volume reaches $4 \%$ hydrogen.

Decreasing the diffusion resistance increases the allowable shipping window. For example, the use of filtered bags reduces the initial hydrogen concentration of the innermost layer to $0.2 \%$ and decreases the rate of accumulation of hydrogen which increases the allowable shipping time to 60 days. Figures 2 and 3 compare changes in the hydrogen gas concentration with time for taped bag and filtered bag enclosures. The amount of material corresponds to 0.25 watts with $3 \%$ moisture and a $G$ value of 0.33 is assumed. Note that the concentration at time zero is the steady-state concentration prior to loading the shipping container. Figures 4 and 5 show the allowable shipping times before the hydrogen concentration in the inner slip lid can reaches the LFL as functions of the $G$ value (moisture) and the heat generation rate.

\section{CONCLUSION}


A conservative approach to quantify hydrogen generation from plutonium bearing oxide materials and subsequent accumulation in multiple layers of confinement is presented. Some general lessons or rules of thumb are:

for dry materials (less than $0.5 \%$ moisture) taped bags are sufficient for plutonium oxide materials less than 5 watts

filtered bags should be considered for wet or larger quantities of plutonium oxide materials

shipping times must be restricted to ensure accumulation of hydrogen above the LFL ( $4 \%$ by volume) does not occur

the approach of restricting shipping times is not applicable to transport over public roads where regulatory requirements prescribe a 1 year time limit

Obviously, a better understanding of hydrogen generation and accumulation from plutonium bearing oxides are needed.

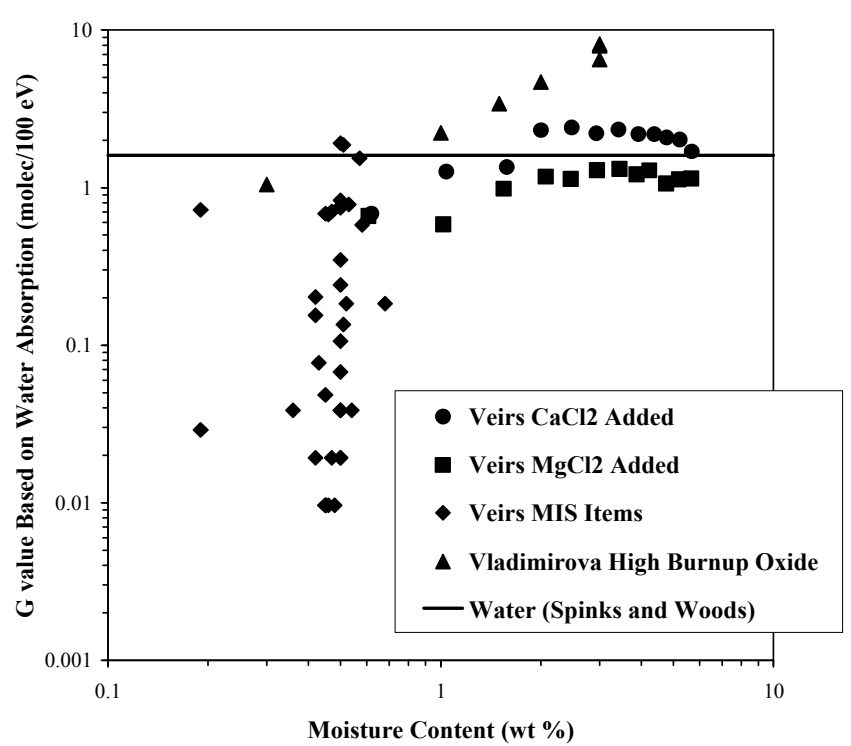

Figure 1. Variation of $\mathrm{G}$ Values for Hydrogen Generation with Water Content ${ }^{2,3,4}$ and Comparison with G Value for Alpha Radiolysis of Liquid Water (Spinks and Woods [5])

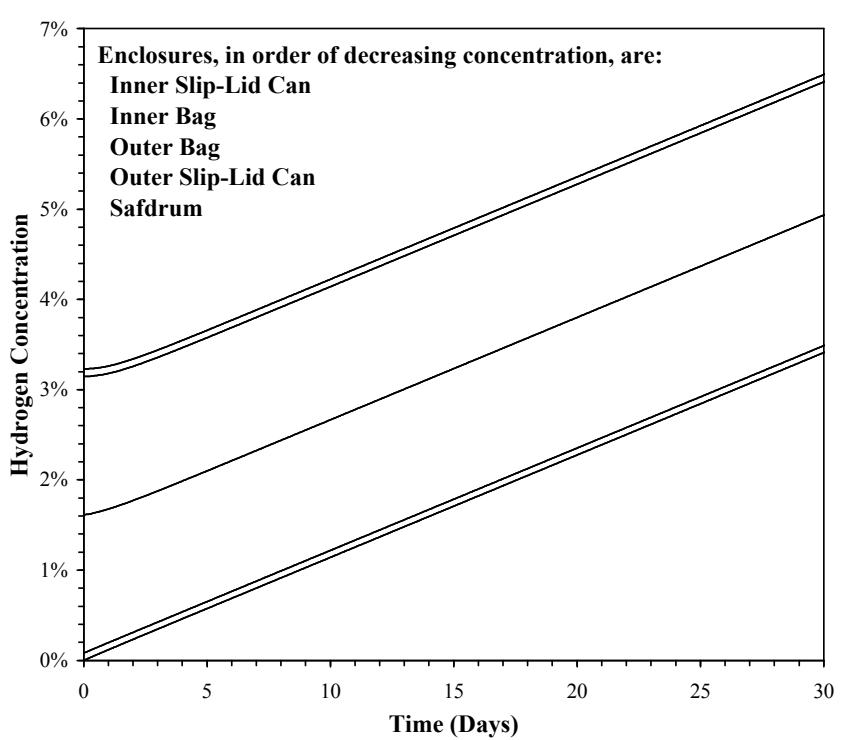

Figure 2. Increase in Hydrogen Gas Concentration for a Slip Lid Can with Taped Bag Enclosures

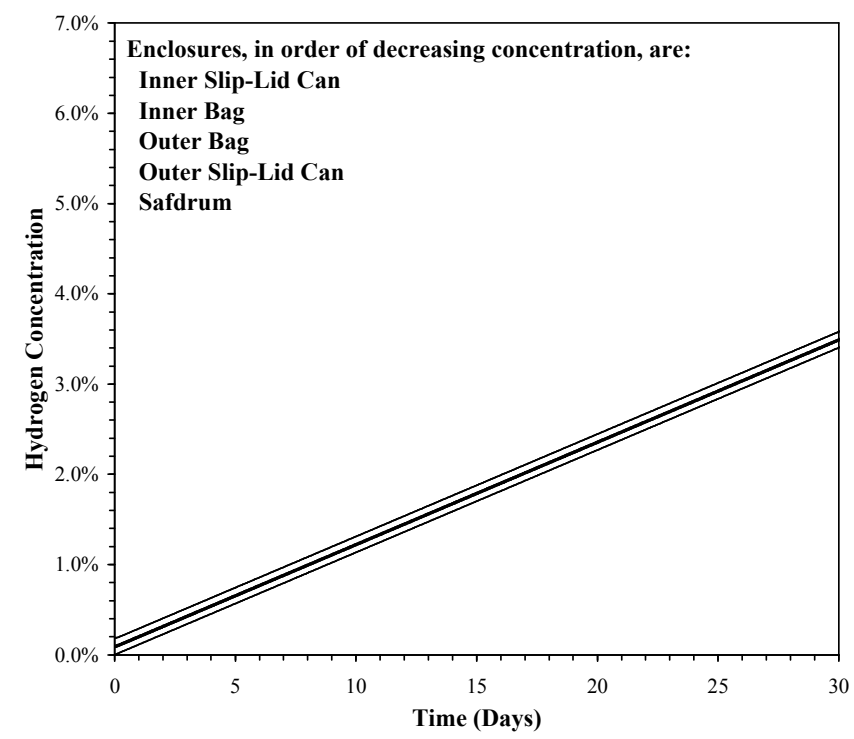

Figure 3. Increase in Hydrogen Gas Concentration for a SlipLid Can with Filtered Bags 


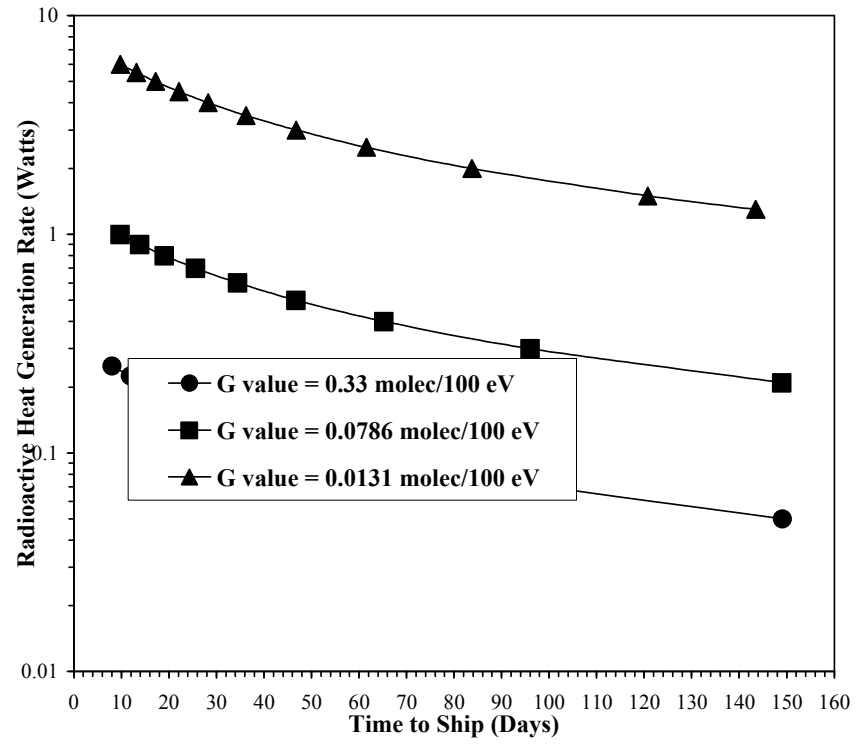

Figure 4. Correlation of Allowable Time to Ship with Radioactive Heat Generation Rate for a Slip-Lid Can with Tape Bag Enclosures

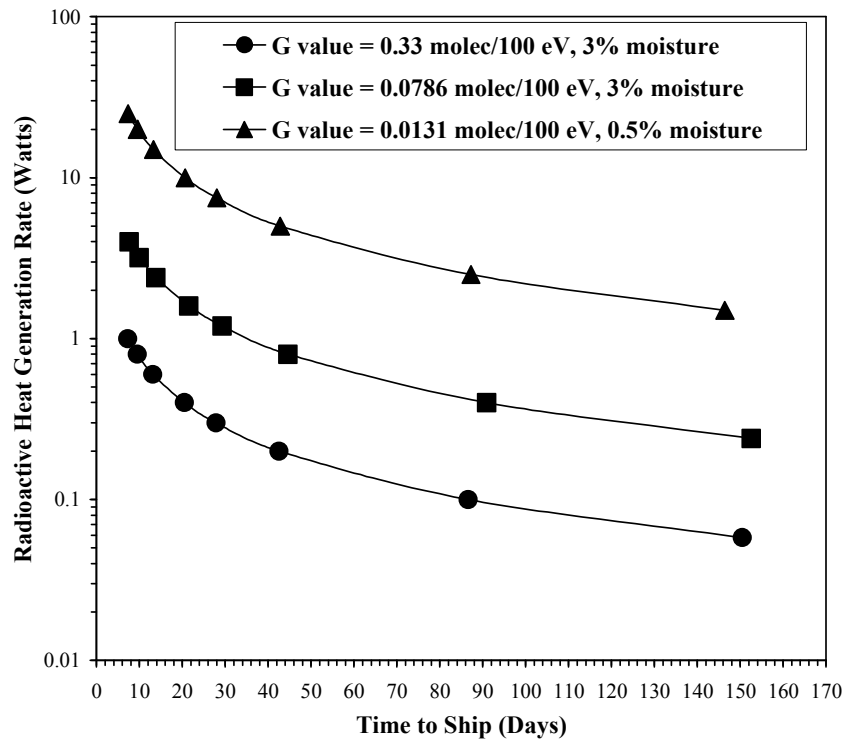

Figure 5. Correlation of Allowable Time to Ship with Radioactive Heat Generation Rate for a Slip-Lid Can with Filtered Bags

\section{ACKNOWLEDGMENT}

This manuscript has been authored by Savannah River Nuclear Solutions, LLC under Contract No. DE-AC0908SR22470 with the U.S. Department of Energy. The United States Government retains and the publisher, by accepting this article for publication, acknowledges that the United States Government retains a non-exclusive, paid-up, irrevocable, worldwide license to publish or reproduce the published form of this work, or allow others to do so, for United States Government purposes.

\section{REFERENCES}

1. H. F. Coward and, G. W. Jones, "Limits of Flammability of Gases and Vapors." Bureau of Mines Bulletin 503, 1952.

2. E. Kelly, L. Peppers, D. K. Veirs, and J. Berg, "3013 Container Statistical and Judgmental Samples Selected for Non-Destructive Evaluation (NDE) in FY 2005," Los Alamos National Laboratory Document LA-UR-05-2193, March, 2005.

3. E. L. Garcia, M. A. Martinez, D. K. Veirs, J. M. Berg, and L. A. Worl, "Small-Scale Studies: Oxygen Generation and Corrosion," Los Alamos National Laboratory Document LA-UR-07-1371, January, 2007.

4. M. V. Vladimirova and I. A. Kulikov, "Formation of $\mathrm{H}_{2}$ and $\mathrm{O}_{2}$ in Radiolysis of Water Sorbed on $\mathrm{PuO}_{2}$." Radiochemistry (Eng. transl. of Radiokhimiya), Vol. 44, No. 1, pp. 83-86, 2002.

5. J. W. T. Spinks and R. J. Woods, Introduction to Radiation Chemistry, $3^{\text {rd }}$ ed., John Wiley \& Sons, New York (1990).

6. "DOE Standard: Stabilization, Packaging, and Storage of Plutonium-Bearing Materials," DOE-STD-3013-2004, April, 2004.

7. T. J. Wickland, M. Mataya, "Hydrogen Diffusivity through Three Types of Tape Seal on a Vollrath 88020 Stainless Steel Slip-led Dressing Container." Waste Management Conference, Tuscon, AZ, March 1997.

8. Safety Analysis Report for the TRUPACT-II Shipping Package., Nuclear Packaging, Inc., pp. 3.6.9-5 - 3.6.9-12, 1989. 